\title{
CASE OF TUMOUR OF PONS AND LEFT CRUS CEREBRI.
}

BY SEYMOOR J. SHARKEY, M.D., F.R.C.P.

W. B., aged 43, sailor, was admitted into St. Thomas's Hospital under my care on January 22, 1892, and died on the 25th of the following May.

His family history presented no features of importance. He had had malarial fever eight years previously, but had never had syphilis. Three years ago he fell from a height of twenty-eight feet, landing on his feet and fracturing his leg near the ankle, but not injuring his head in any way.

Three months and a half ago when in the Gulf of Mexico he began to perspire so freely that it became a subject of general remark. $\mathrm{He}$ got rather stupid, and used to knock against objects on turning to his right. Soon after he became deaf in the right ear, and suffered from numbness all down the right half of his body, the face and head being the last parts affected.

On admission he was found to have right hemianopsia, deafness in the right ear, and paralysis of the superior rectus in each eye, and the right pupil was larger than the left. Both pupils reacted to light and accommodation, but sluggishly. There was no optic neuritis.

The right ear was completely deaf, bone as well as air conduction being abolished.

There was not only numbness over the whole right side of the body, but tactile sensation was also diminished. Sense of temperature was likewise altered, and the only difference he noticed between hot and cold things applied to the right side, was that the former gave rise to a pricking sensation. Muscular sense was normal, and there was no loss of power, except perhaps in right hand. Taste and smell were not materially altered. Superficial and deep reflexes presented no marked chenges. Memory said by patient to be defective, but it was not very obviously so. Speech was rather thick, and there was a 
tendency to stammering. Gait was somewhat peculiar, the right foot being raised higher than the left, and the heel striking the ground first. But this might have resulted from a partial ankylosis of ankle joint due to the old injury.

No inco-ordination or giddiness.

Profuse perspiration present, but no visceral disease detected.

During the first few days in hospital he suffered sometimes from bad headache, sometimes became strange in manner, and noually kept his left eye nearly closed, and the latter peculiarity remained unaltered till he died. He was, however, generally pleasant, and humorous, and much inclined to talk, but his memory got worse and some aphasia supervened.

On February 1, he had forgotten the name of his last ship and captain, though he said he knew them quite well, but could not say them. When shown a candlestick and quill-pen, he was unable to name them, though he named a button correctly. When asked whether the candlestick was a watering can he became very angry, and said the question was childish and ridiculous.

On February $12 \mathrm{Mr}$. Lawford saw him and said he could read with each eye, and with one as well as the other. He could understand what he read and could write. Loss of power in both superior recti and in inferior oblique of right eye.

On February 15 Mr. Nettleship examined him and noted that there was no movement of the eyes upward beyond the horizontal, and that downward movements were also defective, more in right than in left eye. Concomitant lateral movements full, but convergence very defective, and more so in right than in left eye. Irregular nystagmus in lateral and in upward movements. Right pupil larger than left. State of accommodation doubtful. No ptosis; but left palpebral fissu re always narrower than right. As to diplopia, patient appeared to say nothing about it, and be could not with any certainty be got to see double, at any rate not in such a manner as would agree with paresis of right internal rectus.

R. reads $6 \mathrm{~J}$. at $14^{\prime \prime}$
C. $+3 \mathrm{D} .=1 \mathrm{~J}$. at $9^{\prime \prime}$
L. reads $14 \mathrm{~J}$. at $14^{\prime \prime}$
c. $+4 \mathrm{D} .=1 \mathrm{~J}$, at $9^{\prime \prime}$
Together $=6 \mathrm{~J}$. at $14^{\prime \prime}$

c. $+3 \mathrm{D} .=1 \mathrm{~J}$. at $9^{\prime \prime}$, but prefers to shut left eye.

R. V. $=\frac{\theta}{12}:$ Hm. 1D.

L. V. $=\frac{6}{18}:$ No Hm.

Not tried with cylinders. 
240 ORIGINAL ARTICLES AND CLINICAL CASES.
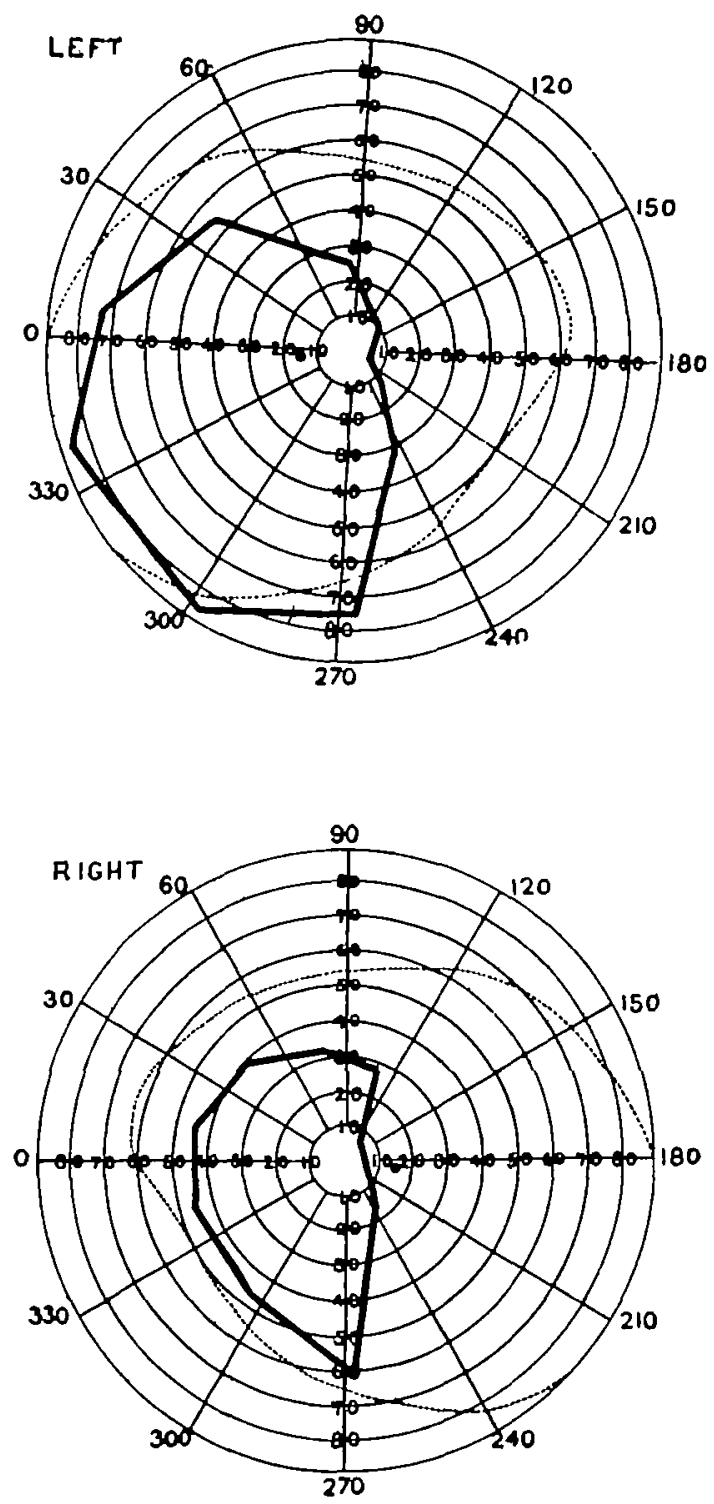

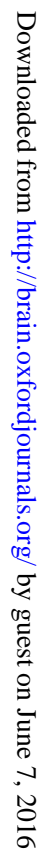




\section{Fundi normal.}

Loss of memory and mental power well marked. When told to sit on his locker he could not be got to understand what was wanted; nor could he say anything he wished to say. There was no muscular paralysis, but very evident anæsthesia, as he could not feel a pin stuck into his right arm. Always yewning.

On February 27 I made the following note :-

"There is distinct loss of power in the right side of face in lower part, the left side being drawn up on laughing, the right not. Tongue protruded straight. Movements of eyes good laterally, much limited in upward direction, (?) somewhat in downward direction too. Both hands grasp poorly, right less strongly then left. Legs fairly strong, but still probably not normally so; right not quite as good as left. Knee-jerks good; no clonus. Intellect very dull at times ; cannot remember the names of blotting paper, pen, \&c., and speech is hesitating and stuttering. So forgetful of words is he that he cannot carry on a conversation. No fits. Dises normal."

March 5.-Mental condition varies a good deal, being much better on some days than on others. Yesterday he was found sitting up in bed eating a crust of bread which he said was a pine, which he was enjoying very much; all the time he was holding his left hand below it to prevent the juice from falling on the bedclothes.

He was getting very drowsy. He could not now touch his nose with his eyes closed, or make his index fingers meet in the middle line, nor could he imitate movements made with his legs, though he was sometimes able after much thought to say which of his legs was uppermost.

On March 10 I made the following note:-

"Patient cannot read printed or written characters; he can make out a word or two here and there, but little more than that, and he appears to lack entirely the power of attention necessary for continued attempts. He cannot write. He very rarely names ordinary objects aright, and he does not seem to think it extraordinary if asked whether a book is an orange, apple, \&c. Still he occasionally says a few sentences correctly. He is very goodhumoured. Optic discs a little hazy, and streaked on internal border; (?) optic neuritis."

March 15.-Optic neuritis evident in both eyes. Attempt to take the field of vision had to be absndoned as he could not be got to understand what was wanted. His mental powers varied very markedly from day to day. For instance, on March 18 he named 
a bunch of keys, a watch, a knife and a pen, and said he knew other things, but that his head was " mixed." On the 21st, he could not even remember his own name. At other times, e.g., March 31, he called things by wrong names; a hair brush an egg brush, a comb an egg brush, blotting paper a cork.

April 7.-Patient could not now feed himself ; urine passed unconsciously sometimes; great drowsiness. Right side evidently weaker than left; clonus sometimes obtained in right foot.

April 28. - In much the same condition, at times making intelligent answers, at others unable to understand what is said to him and giving irrelevant replies; sometimes unable to pronounce words properly.

May 19.-Mentally much the same, but physically very weak ; unable to sit up for any length of time.

May 24.-Very drowsy; by 5 p.m. comatose with stertorous breathing, and temperature $103 \cdot 4^{\circ}$, pulse 132 . He recovered a little and the temperature fell, but soon rose again, reaching before death $106 \cdot 2^{\circ}$, the pulse 200 , and deep coma supervening.

Autopsy.-The brain was the only organ found diseased, and after a rough examination it was put aside to harden in alcohol. On looking at the hemispheres it was seen that the left was larger than the right, but the convolutions, nerves, and vessels on both sides were normal. Where the crura cerebri emerged from the pons on the under surface of the organ the left crus was seen to be much larger than the right, measuring $1 \frac{1}{2}$ inch across, while the right only messured $\frac{3}{4}$ inch. The left optic tract was much flattened as it ran over the left crus cerebri.

On dividing the corpus callosum and separating the hemispheres the left crus was again seen to be very large. The corpora quadrigemina and the roof of the aqueduct of Sylvius were unrecognisable, their place being occupied by a new growth, irregular on the surface and continuous with the left crus cerebri. The whole space between the anterior and upper border of the cerebellum and the third ventricle was filled up by the tumour. The superior crura of the cerebellum could, however, be seen emerging from the tumour apparently healthy, and entering the cerebellum. The floor of the fourth ventricle viewed from above appeared to be normal. After the brain bad been hardened in alcohol, sections were made. 
Section 1 passed through the pons varolii vertically just beyond its junction with the medulla oblongata. The right half of the pons appeared to be healthy, but the fourth ventricle was pushed far to the right by the tumour which grew from the left half of the roof of the aqueduct of Sylvius, but the roof itself and the superior cerebellar pedancle seemed thin and healthy, as did also the greater part of the left half of the pons. The root of the tumour seemed, however, to invade the floor of the fourth ventricle.

Section 2 made vertically, $\frac{1}{8}$ inch posterior to the emergence of the crura cerebri from the pons showed the aqueduct of Sylvius pushed far to the right, the tumour involving the roof of the aqueduct and left half of pons above the locus niger (fig. 1).

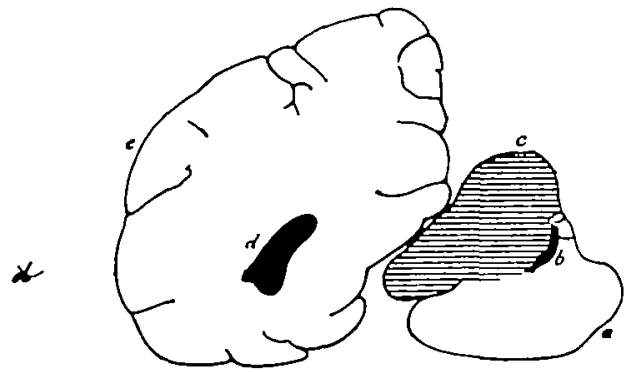

Fig. 1 (Section 2).

a. Pons varolii. b. Aqueduct of Sylvius. c. Shaded tumour.
d. Lateral ventricle.
e. Left hemisphere.

Section 3, made vertically through the crura cerebri about $\frac{1}{4}$ inch beyond their point of divergence, showed the right crus healthy, and the upper or dorsal part of the left entirely occupied by the tumour. The latter had obliterated the posterior part of the internal capsule, the optic thalamus, and part of the extraventricalar nucleus of the corpas striatum. The hippocampal convolution was intact (fig. 2).

Section 4 just in front of corpora mammillaria. The optic thalamus, tail of caudate nucleas, and internal capsule appeared intact, the tumour appearing only in a small area 
of the section and involving part of the extraventricular nucleus.

Section 5 through head of caudate nucleas just behind the anterior extremity of the third ventricle. It showed the internal capsule healthy, and slight involvement of the outer and lower part of the extraventricular nucleus.

Section 6 vertically through Broca's convolution showed nothing abnormal.

The following résumé of the order of appearance of the symptoms helps one to realise how easy it was to come to a conclusion as to the exact position of the tumour.

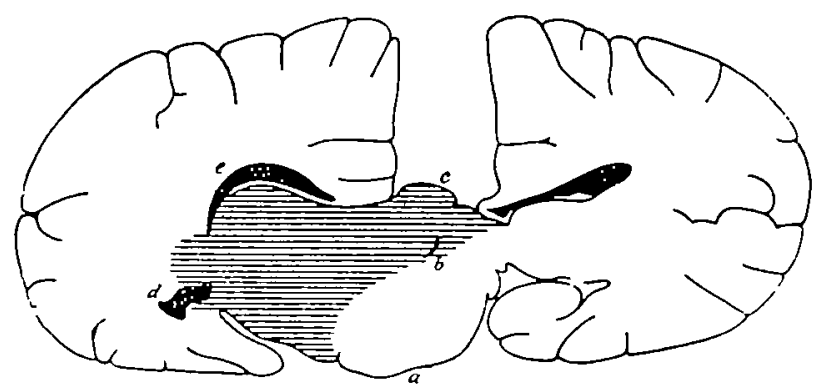

Fig. 2 (Section 8).

a. Pons, varolii. b. Aqueduct of Sylvius. c. Shaded tumour. d. Lateral ventricle. e. Left hemisphere.

Three and $\mathfrak{a}$ half months before admission:-Profuse perspiration ; paralysis of superior recti of eyes (it is probable that this existed early, though only proved to exist on admission into hospital. It is not a paralysis likely to arrest the attention, and no remark was made by the patient with reference to it); hemianopia; deafness ; numbness in right side.

On admission, January 22, 1892, he was found in addition to be suffering from alteration of sense of touch; alteration of sense of temperature (but no alteration of taste or smell); thickness of speech ; difference in size of pupils; headache; failure of memory. 
February 1.-There were found mental weakness; aphasia; atter loss of memory for words; drowsiness.

Febmuary 27.-Right facial paresis.

March 5.-Loss of taste (probably); loss of muscular sense.

March 10.-Alexia; agraphia; optic neuritis.

April 7.-Partial right hemiplegia.

May 19.-Great physical weakness.

May 24.-Coma; hyperpyrexia; death.

The paralysis of the superior recti of both sides, together with hemianopia, deafness and numbness on right side could scarcely be explained except by disease of the floor of the aqueduct of Sylvins gradually invading the left crus cerebri and internal capsule. The successive changes in the patient's condition indicated greater and greater involvement of the nerves of sense, special as well as general, and subsequently disorganisation of the more distant motor tract. It was not until late, when the tumour had reached considerable dimensions, that optic neuritis supervened.

The profase perspiration which marked the onset of the disease, and then disappeared, is very interesting with reference to the question of the existence of sweat centres.

Another very remarkable point is the gradual abolition of mental power and of those functions which are the special attributes of the left cerebral hemisphere, owing to the cutting off of its sensory connection with the exterior, and that notwithstanding the integrity of the hemisphere itself, and that of the corpus callosum which should put it into free communication with the right hemisphere. The mental defects were very marked three months even before his death. 